\title{
Influence of Psychopathologies on Craniomandibular Disorders
}

\author{
Priscila Pitta PENNA \\ Mário RECUPERO \\ Carlos GIL
}

Department of Prosthodontics, Dental School, University of São Paulo, São Paulo, SP, Brazil

\begin{abstract}
Psychopathologies play a role in the etiology and maintenance of craniomandibular disorders (CMD). In this study, the craniomandibular index was applied to valuate signs and symptoms of CMD in 60 dentate patients, who were assigned to 2 groups: symptomatic $(n=35)$ and asymptomatic $(n=25)$. An interview on psychopathologies was carried out with the aim to detect the presence of some mood disorders, such as depression, dysthymic and bipolar I disorders. Among these disturbances, depression was the most significant aspect to be reported $(\mathrm{p}<0.05)$ since it was present in most symptomatic patients. This important interaction was also significantly correlated $(\mathrm{p}<0.05)$ with the Palpation Index. These results suggest that psychopathological aspects could increase muscle tenderness and pain in addition to sleep dysfuntions and other physical complaints. Therefore, psychopathologies should be regarded as an important aspect in patients with orofacial pains.
\end{abstract}

Key Words: craniomandibular disorders, psychopathologies, mood disorders.

\section{INTRODUCTION}

Craniomandibular disorders (CMD) are considered as a result of changes in the stomatognathic system involving the masticatory muscles, as well as the cervical muscles that are responsible for the head postural position and/or temporomandibular joint (TMJ). All these anatomic structures may be subjected to morphological alterations that occur as an adaptative response to eventual modifications in the functionality of the masticatory system $(1,2)$.

Such modifications may be caused by occlusal disturbances due to loss of teeth, presence of premature contacts or other interferences leading to a mandible unstabilization against the maxilla, originating eccentric positions and movements (3-5). Moreover, situations of personal emotional stress of varied origin may also be the underlying cause of muscle tenderness and/or pain, often related with orofacial parafunctional habits and/ or gnashing of teeth (6-9).

The individual response to an external stimulus could be considered as extremely particular and related to the development of some psychopathologies such as depression, anxiety and adjustment disorders (9-11). These disturbances could cause either mental or physical alterations, represented by changes in mood, appetite, stress, fatigue, psychomotor agitation, irritability, sleeping dysfunctions, and muscle tenderness, among other characteristic symptoms (12).

Psychopathologies can lead to an increase of somatic tension, which could, in turn, be the cause of development or increase of orofacial painful symptoms $(7,9,13)$. Therefore, it could be expected that patients presenting both abnormal occlusion and psychopathologies would be more frequently subjected to development of orofacial disorders, including the cases of chronic pain (1,3-5).

Based on these considerations, the purpose of the present study was to determine the existence of a relationship between some psychopathological disturbances and the occurrence of painful symptoms in the orofacial region. 


\section{MATERIAL AND METHODS}

Sixty individuals (mean age $=33$ years) were selected. All patients presented normal occlusion with complete dentition or short fixed partial dentures, good periodontal health, absence of active carious lesions, occasional presence of small diastemas, absence of open bite, anterior and posterior crossbite or any other characteristic related to evident malocclusion.

The individuals were divided according to the presence or lack of CMD signs and symptoms, thus forming an asymptomatic control group $(\mathrm{n}=25)$ and a symptomatic group $(n=35)$. Men and women were equally represented in the control group, while women represented $80 \%$ of the symptomatic group.

CMD signs and symptoms were identified by applying the Craniomandibular Index (CMI) (14). It represents the sum of the Dysfunction Index (DI), which includes items related to limits in range of motion, deviation and/or pain in movement, TMJ noise during movement, and TMJ tenderness, with the Palpation Index (PI), which reflects muscle tenderness at distinct anatomical sites during intraoral palpation of jaw muscles and extraoral palpation of jaw and neck muscles.

Further analysis of psychopathologies was made by clinical interviews elaborated following the 4th edition of the Manual of Statistics and Diagnosis of Mental Disorders (SCID). This psychiatric test allows the detection of a depressive disorder (major depressive episode), a bipolar I disorder and/or a dysthymic disorder (12).

Data were analyzed statistically by Mann-Whitney and Student's t tests at a significance level of 5\%.

\section{RESULTS}

As shown in Table 1, the manifestation of an existing major depressive episode was positively correlated with the symptomatic group ( $<<0.05$; nonparametric Mann-Whitney test). Likewise, depression was significantly $(\mathrm{p}<0.001)$ associated with the Palpation Index $(\mathrm{PI}=0.664)$, and also with the Craniomandibular Index $(\mathrm{CMI}=0.486)($ Table 2; Student's t test $)$. On the other hand, past depression reports showed no significant correlation (Tables 1 and 2) with CMD.

Table 1. Comparison between symptomatic (pain) and asymptomatic (no pain) groups, regarding the presence of psychopathologies (mood disorders).

\begin{tabular}{lcccc}
\hline Groups & Depression & Past depression & $\begin{array}{c}\text { Dysthymic } \\
\text { disorder }\end{array}$ & $\begin{array}{c}\text { Bipolar I } \\
\text { disorder }\end{array}$ \\
\hline $\begin{array}{l}\text { Pain } \\
(\mathrm{n}=35)\end{array}$ & 10 & 14 & 4 & 1 \\
& $28.6 \%$ & $40.0 \%$ & $11.4 \%$ & $2.9 \%$ \\
$\begin{array}{l}\text { No pain } \\
(\mathrm{n}=25)\end{array}$ & 0 & 5 & 0 & 0 \\
& $0.0 \%$ & $20.0 \%$ & $0.0 \%$ & $0.0 \%$ \\
$\mathrm{p}$ value & 0.004 & 0.103 & & 0.083 \\
\hline
\end{tabular}

Table 2. Comparison of psychopathologies (mood disorders) according to dysfunction index (DI), palpation index (PI) and craniomandibular index (CMI).

\begin{tabular}{|c|c|c|c|c|c|}
\hline \multicolumn{2}{|c|}{ Variable } & \multirow{2}{*}{$\begin{array}{c}\text { Depression } \\
n=10\end{array}$} & \multirow{2}{*}{$\begin{array}{c}\text { Past depression } \\
n=19\end{array}$} & \multirow{2}{*}{$\begin{array}{c}\begin{array}{c}\text { Dysthymic } \\
\text { disorder }\end{array} \\
n=4\end{array}$} & \multirow{2}{*}{$\begin{array}{c}\begin{array}{c}\text { Bipolar I } \\
\text { disorder }\end{array} \\
\mathrm{n}=1\end{array}$} \\
\hline \multirow{4}{*}{$\begin{array}{l}\text { Mean } \\
\text { value }\end{array}$} & & & & & \\
\hline & DI & 0.308 & 0.233 & 0.346 & 0.423 \\
\hline & PI & 0.664 & 0.443 & 0.653 & 0.917 \\
\hline & CMI & 0.486 & 0.324 & 0.4995 & 0.670 \\
\hline \multirow{3}{*}{$\begin{array}{c}\mathrm{p} \\
\text { value }\end{array}$} & DI & 0.019 & 0.227 & 0.063 & 0.176 \\
\hline & PI & $<0.001$ & 0.158 & 0.043 & 0.060 \\
\hline & CMI & $<0.001$ & 0.127 & 0.038 & 0.089 \\
\hline
\end{tabular}


Dysthymic disorder was positively $(\mathrm{p}<0.05)$ associated with PI and CMI (Table 2). Although present only in the symptomatic group (Table 1), dysthymia did not reach a significant level $(\mathrm{p}=0.083)$. Another psychiatric disorder, the bipolar I disorder, demonstrated significantly higher scores for signs and symptoms of CMD (Table 2), but this disturbance was not common $(\mathrm{n}=1$; Table 1$)$.

\section{DISCUSSION}

Mood disorders are clinical manifestations of major depressive episodes such as dysthymic and bipolar I disorders (alternate co-existence between depression and manic) (12). According to the results (Table 1), by analyzing the sample as a whole, the current major depressive episode demonstrated an extremely significant relationship $(p<0.001)$ with the CMD. This condition of mood disorders was statistically significant only in the symptomatic group $(\mathrm{p}<0.005)$ where as many as $28.6 \%$ of the patients presented this kind of psychopathology and were suffering from depression that persisted at least 15 days in a roll throughout long-lasting periods $(7-9,15,16)$.

During the psychical tests (SCID) these patients reported 5 or more characteristic symptoms of major depressive episodes such as the permanent presence of a depressed mood during most part of the day, and markedly diminished interest in once considered pleasant activities. Other reported symptoms were either gain or natural loss of weight, insomnia or hypersomnia, psychomotor agitation or retardation, fatigue or loss of energy, feelings of either worthlessness or inappropriate guilt, diminished ability of thinking or attentiveness, indecisiveness, as well as recurrent thoughts of death. In more serious cases, it is expected that these symptoms have an impact on the social and occupational activities in important areas of the individuals' personal lives (12). On this regard, it was observed that, by interfering with basic physiological functions like nutrition, and probable lack of appetite and sleep, depression would generally harm these patients health $(11,13)$. The insomnia usually reported by the patients during their major depressive episodes could result in impairment of the immunological and restoring functions of the organism, since some important substances with a role in these functions are known to be released during sleep $(9,16-18)$.

All together, the negative effects of mood dis- orders, which interfere with the individual's physical, mental and social balance, and consequently originate psychological stress, would establish a vicious cycle, where sensibility to pain, and its intensity and severity, would be augmented as to take over the daily life of these persons $(11,13,14)$. The resulting increase of emotional stress, reflected as anxiety associated with depression, would contribute to the maintenance of the pain, then closing the vicious cycle $(7,8,15,16,19)$.

The analysis of PI in depressive patients did reveal high levels of somatization (Table 2) as well as the occurrence of bipolar I disturbance, a mental disorder marked by alternating extremes of excitement and depression (Table 2). In comparison to the control group, the patients with a major depressive episode $(n=10)$ presented an exacerbation of muscle tenderness and pain $(p<0.001)$, and high mean PI (approximately 0.664) (Table 2). Likewise, bipolar I disturbance, although occurring less frequently than depression $(n=1)$, presented the highest PI (Table 2). It is interesting to point out that all patients suffering from depression and bipolar I disturbance, also presented a related symptom of anxiety. Nevertheless, this anxiety cannot be regarded as the main psychopathology, since it would be a result of the emotional distress generated by depression associated with physical and psychosocial complains (12). This scenario arose from detailed analysis of the patient's data collected during the psychiatric tests, necessary to diagnose the current psychopathologies.

Therefore, the high PI would be the clinical representation of the emotional distress, originated by a depressive disorder somatized in the jaw and neck muscles, which could in turn result in tension headache $(7,8,11,13,17)$. This information depicted from the present study gains force with data collected by other authors relating depression with CMD of muscular origin, and not with articular problems $(2,9,15,20)$.

This relation would be better understood comparing the DI in Table 2, which reflects TMJ tenderness and functioning problems (14). According to Table 2, depression presents a significant association $(\mathrm{p}<0.05)$ with DI. However, its association with the etiology of articular problems could not be confirmed, once they usually involve TMJ morphological alterations, sometimes permanent $(1,2,9,20)$. Therefore, in order to establish a relation between depression and DI, the patients with past experienced depression should present a statically significant DI, which do not occur ( $p>0.05$ ) (Table 2). 
In the same way, data on Table 2 show that past major depressive episodes did not have an important relation either ( $p>0.05)$ with the development of muscle pain symptoms concerning CMD. Even so, the past major depressive episodes may play an important role in the etiology of psychopathologies, since regardless the presence of symptoms, as many as $68 \%$ of the patients reporting priory depression experiences also presented current psychopathology by the time of this survey $(11,15,19)$.

This analysis confirms the need of investigating past depressive episodes as a factor that could expose some subjects to future psychopathologies. This would occur due to permanent biological alterations in their brains, making them vulnerable to external stressing agents (12).

The depressive disorder consists of strong manifestation of depression symptoms. However, we have a dysthymic disturbance when these symptoms appear in a milder and chronic way, lasting for years. In this study, the dysthymic disorder was positively although weakly associated with CMD (Table 1). Nonetheless, the coexistence of this disturbance with a major depressive episode could be considered as very common, and so resulting in a double depression, generally leading to a bad diagnosis (12).

In the present study, the general sampling showed the presence of dysthymia in $6.7 \%$ of the patients that were sensitive to CMD, presenting a statistically significant association with CMI $(\mathrm{p}<0.05)$ (Table 2). Despite finding a positive correlation between PI and CMI with dysthymic disorder (Table 2), the only feasible conclusion is that these patients would probably present a CDM chronic manifestation. This conclusion is based on the data presented herein concerning the influence exerted by depression on CMD painful symptoms (Table 2). Therefore, a chronic manifestation of typical depression symptoms together with anxiety would be associated with the occurrence of long-lasting pain $(11,15,19)$. This clinical condition could harm the stomatognathic system, as observed in the patients in this study by their high mean DI (Table 2).

Overall, the findings of this study suggest that the presence of a major depressive episode is strongly correlated with the increase of muscle painful tenderness in patients with CMD symptoms. Furthermore, the other psychopathologies evaluated in the present study, namely dysthymic and bipolar I disorders, showed a direct influence on the CMI values.

\section{RESUMO}

Os transtornos psíquicos podem desempenhar um importante papel na etiologia e manutenção das desordens craniomandibulares (DCM). Desta forma, neste estudo, foi aplicado o índice craniomandibular (ICM), o qual permite detectar a presença de sinais e sintomas de DCM em 60 pacientes totalmente dentados. Estes pacientes foram divididos em dois grupos: sintomáticos $(n=35)$ e assintomáticos $(n=25)$. Um teste psiquiátrico foi administrado para diagnosticar patologias psíquicas pertencentes ao DSM-IV, como a depressão e os transtornos distímico e bipolar I. Das patologias psíquicas relacionadas aos transtornos de humor, a depressão mostrou uma relação estatisticamente significante $(\mathrm{p}<0,05)$ com os pacientes sintomáticos para DCM. Ao analisar o índice de palpação separadamente, essa relação se manteve significante $(\mathrm{p}<0,05)$ numa escala crescente de valores, demonstrando a ação destes transtornos sobre a sintomatologia dolorosa muscular. Assim sendo, os transtornos mentais exerceriam uma influência considerável na etiologia da DCM, na medida em que potencializariam a dor. Isso ocorreria em função do aumento da tensão muscular, dos distúrbios do sono e de outras alterações fisiológicas advindas destes transtornos.

\section{REFERENCES}

1. Kino K, Sugisaki M, Haketa T, Amemori Y, Ishikawa T, Shibuya T, et al.. The comparison between pains, difficulties in function, and associating factors of patients in subtypes of temporomandibular disorders. J Oral Rehabil 2005;32:315-325.

2. Wiese M, Svensson P, Bakke M, List T, Hintze H, Petersson A, et al.. Association between temporomandibular joint symptoms, signs, and clinical diagnosis using the RDC/TMD and radiographic findings in temporomandibular joint tomograms. J Orofac Pain 2008;22:239-251.

3. Barker DK. Occlusal interferences and temporomandibular dysfunction. Gen Dent 2004;52:56:61.

4. Le Bell Y, Niemi PM, Jämsä T, Kylmälä M, Alanen P. Subjective reactions to intervention with artificial interferences in subjects with and without a history of temporomandibular disorders. Acta Odontol Scand 2006;64:59-63.

5. Wang MQ, Cao HT, Liu FR, Chen C, Li G. Association of tightly locked occlusion with temporomandibular disorders. J Oral Rehabil 2007;34:169-173.

6. Carlsson GE, Egermark I, Magnusson T. Predictors of bruxism, other oral parafunctions, and tooth wear over a 20-year follow-up period. J Orofac Pain 2003;17:50-57.

7. Gatchel RJ, Stowell AW, Buschang P. The relationships among depression, pain, and masticatory functioning in temporomandibular disorder patients. J Orofac Pain 2006;20:288-296.

8. Gungormus Z, Erciyas K. Evaluation of the relationship between anxiety and depression and bruxism. J Int Med Res 2009;37:547550 .

9. Mongini F, Ciccone G, Ceccarelli M, Baldi I, Ferrero L. Muscle tenderness in different types of facial pain and its relation to anxiety and depression: a cross-sectional study on 649 patients. Pain 2007;131:106-111.

10. Auerbach SM, Laskin DM, Frantsve LM, Orr T. Depression, pain, exposure to stressful life events, and long-term outcomes 
in temporomandibular disorder patients. J Oral Maxillofac Surg 2001,59:628-633.

11. Schur EA, Afari N, Furberg H, Olarte M, Goldberg J, Sullivan PF, et al.. Feeling bad in more ways than one: comorbidity patterns of medically unexplained and psychiatric conditions. J Gen Intern Med 2007;22:818-821

12. Kaplan HI, Sadock BJ, Grebb JA. Mood disorders. In: Kaplan and Sadock's synopsis of psychiatry. 7th ed. Baltimore: Williams and Wilkins; 1994.

13. John MT, Reissmann DR, Schierz O, Wassell RW. Oral health-related quality of life in patients with temporomandibular disorders. J Orofac Pain 2007;21:46-54.

14. Fricton JR, Schiffman EL. The craniomandibular index: validity. J Prosthet Dent 1987;58:222-228.

15. Nifosi F, Violato E, Pavan C, Sifari L, Novello G, Guarda Nardini $\mathrm{L}$, et al.. Psychopathology and clinical features in an Italian sample of patients with myofascial and temporomandibular joint pain: preliminary data. Int J Psychiatry Med 2007;37:283-300.

16. Selaimen CM, Jeronymo JC, Brilhante DP, Grossi ML. Sleep and depression as risk indicators for temporomandibular disorders in a cross-cultural perspective: a case-control study. Int J Prosthodont 2006;19:154-161.

17. Riley JL, Myers CD, Currie TP, Mayoral O, Harris RG, Fisher JA, et al.. Self-care behaviors associated with myofascial temporomandibular disorder pain. J Orofac Pain 2007;21:194-202.

18. Yatani H, Studts J, Cordova M, Carlson CR, Okeson JP. Comparison of sleep quality and psychologic characteristics in patients with temporomandibular disorders. J Orofac Pain 2002;16:221228.

19. Johansson CB, Samuesson N, Dahlström L. Utilization of pharmaceuticals among patients with temporomandibular disorders: a controlled study. Acta Odontol Scand 2006;64:187-192.

20. Schmitter M, Kress B, Ohlmann B, Henningsen P, Rammelsberg P. Psychosocial behavior and health care utilization in patients suffering from temporomandibular disorders diagnosed on the basis of clinical findings and MRI examination. Eur J Pain 2005;9:243250 .

Accepted May 21, 2009 